\title{
Prevalence and Factors Associated with the Anxio-Depressive Symptoms of the Families of Patients in Intensive Care Unit at Gabriel Toure University Hospital, Bamako, Mali
}

\author{
Almeimoune Abdoulhamidou', Mangane Moustapha', Diop Madane Thierno1, \\ Démbele Seydou Aladji ${ }^{1}$, Kassogue André1, Sogoba Youssouf', Dabo Aminata1, \\ Diallo Daouda', Diallo Boubacar ${ }^{3}$, Souleymane Coulibaly4, Diallo H. Seybou' ${ }^{4}$, \\ Maiga Youssoufa ${ }^{2}$, Diango Djibo Mahamane ${ }^{1}$
}

\author{
${ }^{1}$ Department of Anesthesiology and ICU, Hôpital Gabriel Touré, Bamako, Mali \\ ${ }^{2}$ Department of Neurosurgery, Hôpital Gabriel Touré, Bamako, Mali \\ ${ }^{3}$ Department of Anesthesiology and ICU, Hôpital Point G, Bamako, Mali \\ ${ }^{4}$ Psychatric service, Hôpital Pint G, Bamako, Mali \\ Email: abdoulhamidoumaiga@gmail.com
}

How to cite this paper: Abdoulhamidou, A., Moustapha, M., Thierno, D.M., Aladji, D.S., André, K., Youssouf, S., Aminata, D., Daouda, D., Boubacar, D., Coulibaly, S., Seybou, D.H., Youssoufa, M. and Mahamane, D.D. (2018) Prevalence and Factors Associated with the Anxio-Depressive Symptoms of the Families of Patients in Intensive Care Unit at Gabriel Toure University Hospital, Bamako, Mali. Neuroscience \& Medicine, 9, 150-158. https://doi.org/10.4236/nm.2018.93015

Received: August 16, 2018

Accepted: September 16, 2018

Published: September 19, 2018

Copyright $\odot 2018$ by authors and Scientific Research Publishing Inc. This work is licensed under the Creative Commons Attribution International License (CC BY 4.0).

http://creativecommons.org/licenses/by/4.0/

c) (i) Open Access

\begin{abstract}
Introduction: Hospitalization in intensive care is a source of stress and anxiety for close to the patients. Anxio-depressive symptoms appear to be common in intensive care and their prevalence is poorly evaluated. The objective of this study was to evaluate the prevalence of anxio-depressive symptoms in families. Materials and method: Observational prospective study in families of patients hospitalized in the intensive care unit for a period of 5 months. Symptoms of anxiety and depression were measured using Hospital Anxiety and Depression Scale (HADS) during hospitalization. Anxiety and depression were defined by a score greater than 10 . Factors associated with the onset of anxious-depressive symptoms were sought. The prevalence of post-traumatic stress disorder in close relatives was measured by the Impact Event Scale-Revised scale (IES-R). Results: A total of 107 patients were admitted to the intensive care unit, of which 49 families agreed to participate in our study. Overall mortality was $32.2 \%$ during this period. Fifty-eight (58) patients were not included for the following reasons: death or hospitalization of less than 48 hours, refusal of families, institution, and lack of parents speaking French. Forty-nine (49) relatives completed the HADS questionnaire. Forty-three families completed the IES-R questionnaire, a return rate of $87.7 \%$. The prevalence of anxiety was $61.2 \%$ among parents in early hospitalization. The level of anxiety was significantly associated with male parents ( $p$
\end{abstract}


$=0.035)$ and those with lower education $(\mathrm{p}=0.046)$. The prevalence of depressive symptoms in parents was evaluated $53 \%$ at D3. Education level $(\mathrm{p}=$ $0.048)$ and male parents $(\mathrm{p}=0.048)$ appeared to be a significant depression factor. The prevalence of post-traumatic stress disorder was $55.1 \%$ among the relatives of the patients. The lack of co-morbidity in admission patients was significantly associated with the occurrence of post-traumatic stress disorder in the family. Conclusion: The prevalence of anxiety and depression symptoms was high in our study. Men were at greater risk of developing these symptoms. The parents of the patients carburized appear as a population with higher risk manifestation of psychological disorders; further research is needed in this group.

\section{Keywords}

Anxiety, Depression, Resuscitation, Patient Families, Quality Approach

\section{Introduction}

A stay in intensive care is a source of anxiety and depression for the families of patients, which can affect their quality of life. Since anxiety is an objectless fear, it may or may not progress to a pathological condition characterized by a sad and painful mood associated with a reduction in psychomotor activity and an intellectual disinterest defining depression. Post Traumatic Stress Disorder (PTSD) is the result of an individual's exposure to a traumatic event in which they felt intense fear and feelings of helplessness that caused distress. The vital prognosis of the patients is very often engaged in resuscitation. This situation is a traumatic experience for parents who can develop PTSD that affects their quality of life. In recent years there has been a growing interest in improving the quality of life of patients and their loved ones, as indicated in the 6th SFAR-SRLF consensus conference "Better live resuscitation" [1]. In addition, specific care and satisfaction of family centered care families are given special attention by the care teams [2] [3] [4]. Many studies [3] [4] emphasize that the symptoms of anxiety, depression and PTSD affect a large majority of the patient's parents, making this problem a challenge for the resuscitation practitioner. However, this question remains largely undocumented in the African context, particularly in Mali. That is why we proposed to carry out this work; the purpose of which was to evaluate the prevalence and factors associated with the anxio-depressive symptoms and the occurrence of PTSD in parents' of patients. This work aims to identify the probable psychological disorders only in the parents of the patients.

\section{Materials and Method}

This is a prospective, observational study conducted over the period from July 2014 to November 2014 in the resuscitation department of the department of anesthesia resuscitation and emergency medicine of CHU Gabriel Touré. 


\subsection{Criteria for Inclusion}

All relatives of patients who had resuscitated more than 48 hours were eligible. The number of relatives per patient has been set at an adult.

\subsection{Criteria of Non-Inclusion}

Families whose patient had died and/or refused to participate in the study, patients with no visit 3 days after admission and families not proficient in French were not included.

\subsection{Process of the Protocol}

Each family was informed that a study was underway and that they could participate by answering a questionnaire. Hospital Anxiety and Depression Scale (HADS): The HADS questionnaire is a 14-item self-questionnaire developed by Zigmond and Snaith [5] aims to detect symptoms of anxiety and depression. It is quick to complete, easy to understand and evaluate. Seven items evaluate anxiety and 7 others rate depression. Each item is side on a 4 point scale $(0-3)$, the scores range from 0 to 21 for each of the two symptoms. This questionnaire HADS has been validated in French [6] as well as in patients hospitalized in intensive care. Between the 3rd and the 4th day of hospitalization, the parents filled the questionnaire of scale of anxiety and depression (Hospital Anxiety and Depression Scale, HADS). A score greater than 10 expresses an anxiety or depressive state [5]. Impact Event Scale Revised (IES-R): This questionnaire includes 22 items and measures the symptoms of hypervigilance, intrusion cognitive and avoidance. It groups 22 items rated from 0 (not at all) to 4 (extremely) assessing the feeling in the last 7 days. The sum of the scores is from 0 (not of symptom) to 88 (severe symptoms). The IES-R scale has been validated in French [7]. We chose a threshold of 30, correlated value in many studies to an associated post-traumatic stress response at risk of PTSD. The correlation coefficient varies between 0.81 and 0.93 [8]. One week after resuscitation, parents completed the PSTT (Impact Event Scale Revised, IES-R). We chose a threshold of 30 , a value correlated in many studies with a post-traumatic stress reaction associated with a risk of PTSD [7].

\subsection{Variables Collected}

Patients: age, sex, reason for hospitalization, need for emergency surgery, history of chronic illness.

\subsection{Proximity/Parents}

Age, sex, relationship and level of education, assessment of the quality of the information they received, HADS scores at D3 and IES-R scores 7 days after stay.

\subsection{Analysis Plan}

Data entry and analysis: SPSS 19.0 software. The statistical test: the Chi square, 
significant for a value of $\mathrm{p}<0.05$ is a $95 \%$ confidence interval.

\subsection{Ethical Considerations}

Since we have no involvement in the care of patients and whose objective is to improve the practices of the service, we have endeavored to guarantee the confidentiality of participants' data.

\section{Results}

\subsection{Patient Characteristics}

During the study period, 107 patients were admitted to the intensive care unit of which 49 patients were included. Overall mortality was $32.2 \%$ during this period. Fifty-eight (58) patients were not included for the following reasons: death or hospitalization of less than 48 hours, refusal of families, institution, default of French speaking parents. Epidemiologically it was a young patient, mostly female. The main reasons for admission were complications of preeclampsia $34.7 \%(\mathrm{n}=17)$, vaginal trauma $32.7(\mathrm{n}=16)$, postoperative management $22.4 \%$ $(\mathrm{n}=11)$ and medical pathologies $10.2 \%(\mathrm{n}=5)($ Table 1$)$.

\subsection{Characteristics of Parents}

Forty-nine (49) relatives completed the HADS questionnaire between the 3rd and 4th day of hospitalization. Among the six (07) nonrespondent families, a telephone interview was conducted to explain the causes of non-response. The main reason given by relatives who did not answer the questionnaire was due to the fact that they lost it. Forty-three parents completed the IES-R questionnaire at 7 days of hospital discharge, a return rate of $87.7 \%$. Respondent parents were male in more than $2 / 3$ of the cases, in 14 cases this parent was a spouse. In half of the cases, the parents' level of education was lower than the bachelor's degree, however, they were $71.4 \%(\mathrm{n}=35)$ reporting having received clear and understandable information about the illness of their patients (Table 2).

Table1. Characteristics of patients.

\begin{tabular}{ccc}
\hline Characteristics & $\mathrm{n}$ & $\%$ \\
\hline Female ex & 30 & $61.2 \%$ \\
Old (16 - 30 years) & 35 & $71.4 \%$ \\
Length of stay 3 to 5 days & 21 & $42.9 \%$ \\
Preeclampsia & 17 & $34.7 \%$ \\
Severe trauma & 16 & $32.7 \%$
\end{tabular}

Table 2. Characteristics of parents.

\begin{tabular}{ccc}
\hline Characteristics of parents & $\mathrm{n}$ & $\%$ \\
\hline Parent's sex (man) & 31 & $63.3 \%$ \\
Parnt's age (18 - 39 years) & 28 & $57.1 \%$ \\
Spouses & 14 & $28.6 \%$ \\
Parent's level of education (lower than the bachelor) & 26 & $53.1 \%$ \\
Information (clear and understandable) & 35 & $71.4 \%$
\end{tabular}




\subsection{Anxiety and Related Factors}

According to the HADS scale, anxiety was prevalent in $61.2 \%$ of patients' parents. Some factors were frequently associated with this anxiety, including male respondent parents $(\mathrm{p}=0.046)$. The fact that the parents had a patient in intensive care exposed them more to anxiety $(\mathrm{p}=0.387)$. The main pathology associated with anxiety eclampsia $(\mathrm{p}=0.299)$. Parents with lower education were more likely to be anxious ( $\mathrm{p}=0.035)$ (Figure 1 and Table 3 ).

According to the HADS scale, depression was prevalent in $53.1 \%(\mathrm{n}=26)$ of patients' parents. The factors associated with this depression were the fact that families had a young patient in intensive care $(\mathrm{p}=0.853)$ or that the patient's representative was male $(p=0.035)$, the same was true when this representative had a lower education level $(\mathrm{p}=0.046)$ (Figure 2 and Table 4$)$.

\subsection{Post-Traumatic Stress Disorder (PTSD)}

According to Impact Event Scale Revised (IES-R), 55.1\% of Post Traumatic Stress Disorder (PTSD) occurred in $30.6 \%$ of parents who responded to the IES-R questionnaire. This syndrome was particularly found in parents whose patient had no co-morbidity before admission to intensive care $(\mathrm{p}=0.031)$ (Figure 3 and Table 5).

\section{Comments and Discussions}

This study has some limitations:

Table 3. Factors Associated with Anxiety.

\begin{tabular}{cccc}
\hline Factors Associated with Anxiety & $\mathrm{n}$ & Anxiété (\%) & $\mathrm{p}$ \\
\hline Patient's sex (Female) & 18 & $69.2 \%$ & 0.387 \\
Parent's age (18 - 39 years) & 17 & $64.4 \%$ & 0.241 \\
Parent's sex (Man) & 16 & $61.5 \%$ & 0.046 \\
Parent's level education (<Bachelor) & 14 & $53.8 \%$ & 0.299 \\
Reason for admission (Preeclampsia) & 11 & $42.3 \%$ & 0.694 \\
\hline
\end{tabular}

Table 4. Factors Associated with Depression Symptoms (HADS-A > 10).

\begin{tabular}{cccc}
\hline Factors Associated with Depression & $\mathrm{n}$ & Dépression (\%) & $\mathrm{p}$ \\
\hline Patient's sex (16 - 30 years) & 22 & $73.3 \%$ & 0.853 \\
Parent's age (18 - 39 years) & 19 & $63.3 \%$ & 0.183 \\
Parent's sex (Man) & 17 & $56.7 \%$ & 0.035 \\
Parent's level education (<Bachelor) & 16 & $53.3 \%$ & 0.046 \\
Kinship & & & \\
Spouses & 8 & $26.7 \%$ & \\
Fathers and mothers & 8 & $26.7 \%$ & 0.203 \\
\hline
\end{tabular}


Table 5. Factors Associated with the Occurrence Post Traumatic Stress Disorder (PTSD).

\begin{tabular}{cccc}
\hline Factors Associated with the PTSD & $\mathrm{n}$ & PTSD & $\mathrm{p}$ \\
\hline $\begin{array}{c}\text { Comorbidity (Absence) } \\
\text { Reason for admission } \\
\quad \text { (Severe trauma) }\end{array}$ & 22 & $81.5 \%$ & 0.031 \\
Kinship (spouses) = child & 14 & $51.8 \%$ & 0.689 \\
Parent's HADS-A > 10 & 7 & $25.9 \%$ & 0.217 \\
Parents HADS-D > 10 & 17 & $65.4 \%$ & 0.252 \\
\hline
\end{tabular}

\section{HADS-anxiety}

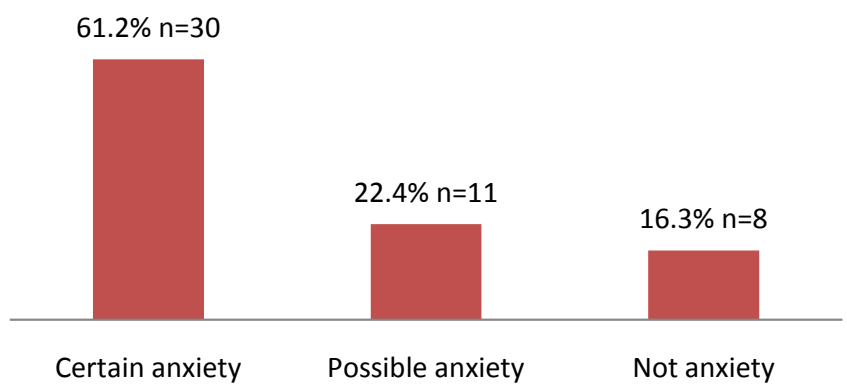

Figure 1. Anxiety prevalence.

\section{HADS-anxiety}

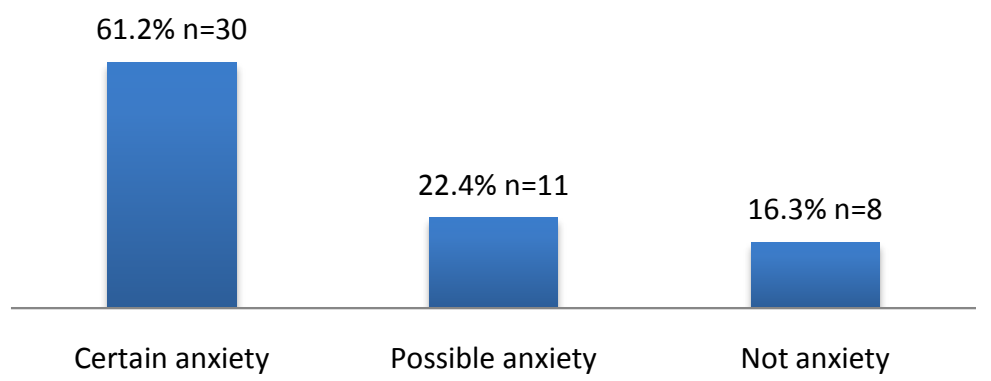

Figure 2. Depression prevalence.

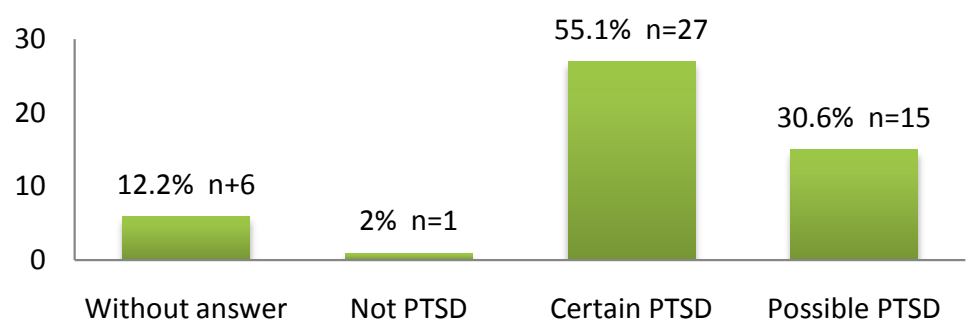

Figure 3. Prevalence of post-traumatic stress disorder.

The factors related to the care and organization of the service were not sought.

We did not evaluate the impact of these psychological disorders on the quality of life of the parents. 
In our study, intensive care was associated with a high prevalence of anxiety symptoms and depression in the parents of patients. These results are similar to several studies, particularly those reported by Pochard et al. in France in 2001 who found a prevalence of anxiety and depression symptoms of $69.1 \%$ and $35.4 \%$, respectively, between the third and fifth day of hospitalization [9]. On the other hand, they are lower than those reported by the Macdam team in Canada in 2010 , which found an $80 \%$ anxiety rate and $70 \%$ depression among close relatives of ICU patients [10]. However, we did not investigate whether the prevalence of anxio-depressive symptoms (ADS) decreased at a distance from hospitalization. This observation confirms the imperative need to take care of these parents of patients at the state of anxiety state at the risk of seeing them develop a more complex depressive state to treat and live. We found that a post-traumatic stress reaction at 07 days was present in $55 \%$ of the parents of patients without being able to demonstrate if it was correlated, at a level of high anxiety-depressive syndromes. This prevalence remains higher than that reported by Chaussard et al. in France in 2012 [11] who found $31.9 \%$ at one month of hospitalization. This could be explained by the fact that we evaluated the IES-R one week after the patients' exit from the resuscitation and that within this period the majority of the patients did not return to their home. These patients, for the most part do not have an independent status, and families must learn to live often with a disabled relative. All these events can be badly lived by the parents and exacerbate in them these psychological disorders. Different authors identify socio-demographic characteristics as predictive factors for ADS development. In our study, we found an association between the male sex, the relationship (spouse) and the occurrence of these ADS during the stay. This gender difference has already been shown in many studies that women appear to be more vulnerable to anxiety and depression [9] [12]. In our series a set of factors could explain this male predominance, including socio-cultural factors. In a family, spouses are most often asked to represent their wives as a trusted person. The great economic precariousness and the burden of care and hospitalization costs of their wives create solvency difficulties. The latter then becomes responsible for the information communicated to other members of the family and spokesperson for his wife regarding medical decisions. This responsibility and emotional charge can be responsible for the development of these ADS. In our cohort, parents with a lower education level were at a higher risk of developing depressive symptoms. Anderson et al. in Canada 2009 [13], and Chausard et al. in France in 2012 [11] show that family members with a low level of education are at risk of developing pathological anxiety. In our study, it was above all the admission for severe traumatic brain injury-cerebral vascular accident that constituted a risk factor for the occurrence of PTSD at 07 days of the resuscitation exit. This result is similar to those published by Pielmaier et al. in Israel in 2005 [14] found that $52 \%$ of families with traumatic brain injuries suffered PTSD 15 days after the accident. Such a frequency of PTSD and ADS could be explained by the fact that 
these traumas and accidents are brutal events, occurring in the majority of the cases in subjects free from pathology and that they are likely to lead to a physical handicap and/or psychic difficult to accept for patients and their loved ones.

\section{Conclusion}

The prevalence of anxiety and depression symptoms was high in our study. Men were at greater risk of developing these symptoms. The parents of the patient carburized appear as a population with higher risk manifestation of psychological disorders; further research is needed in this group.

\section{Conflicts of Interest}

The authors declare no conflicts of interest regarding the publication of this paper.

\section{References}

[1] Fourrier, F. (2010) Mieux vivre la réanimation [Improve Living in the Intensive Care Unit]. Réanimation, 19, 191-203. https://doi.org/10.1016/j.reaurg.2010.03.001

[2] Heyland, D.K., Rocker, G.M., Dodek, P.M., Kutsogiannis, D.J., Konopad, E., Cook, D.J., et al. (2002) Family Satisfaction with Care in the Intensive Care Unit: Results of a Multiple Center Study. Critical Care Medicine, 30, 1413-1418. https://doi.org/10.1097/00003246-200207000-00002

[3] Azoulay, E., Pochard, F., Chevret, S., Lemaire, F., Mokhtari, M., Le Gall, J.R., et al. (2001) Meeting the Needs of Intensive Care Unit Patient Families: A Multicenter Study. American Journal of Respiratory and Critical Care Medicine, 163, 135-139. https://doi.org/10.1164/ajrccm.163.1.2005117

[4] Diango, M.D., Almeimoune, A., et al. (2012) Problématique liée à l'information des familles des patients en milieu de réanimation du CHU Gabriel Toure [Problems Related to Informing Families of Patients in Intensive Care Unit AT CHU Gabriel Touré]. Mali Medical, 17, 66-70

[5] Zigmond, A.S. and Snaith, R.P. (1983) The Hospital Anxiety and Depression Scale. Acta Psychiatrica Scandinavica, 67, 361-370. https://doi.org/10.1111/j.1600-0447.1983.tb09716.x

[6] Rattray, J.E., Johnston, M. and Wildsmith, J.A.W. (2005) Predictors of Emotional Outcomes of Intensive Care. Anaesthesia, 60, 1085-1092. https://doi.org/10.1111/j.1365-2044.2005.04336.x

[7] Brunet, A., St-Hilaire, A., Jehel, L. and King, S. (2003) Validation of a French Version of the Impact of Event Scale-Revised. The Canadian Journal of Psychiatry, 48, 56-61. https://doi.org/10.1177/070674370304800111

[8] Creamer, M., Bell, R. and Failla, S. (2003) Psychometric Properties of the Impact of Event Scale-Revised. Behaviour Research and Therapy, 41, 1489-1496. https://doi.org/10.1016/j.brat.2003.07.010

[9] Pochard, F., Azoulay, E., Chevret, S., Lemaire, F., Hubert, P., Canoui, P., et al. (2001) Symptoms of Anxiety and Depression in Family Members of Intensive Care Unit Patients: Ethical Hypothesis regarding Decision-Making Capacity. Critical Care Medicine, 29, 1893-1897. https://doi.org/10.1097/00003246-200110000-00007

[10] McAdam, J.L., Dracup, K.A., White, D.B., Fontaine, D.K. and Puntillo, K.A. (2010) 
Symptom Experiences of Family Members of Intensive Care Unit Patients at High Risk for Dying. Critical Care Medicine, 38, 1078-1085. https://doi.org/10.1097/CCM.0b013e3181cf6d94

[11] Chaussard, M. (2012) Symptômes anxiodepressifs des familles des patients en réanimation: Prévalence, évolution et facteurs associées. Mémoire de D.E.S. anesthésie-reanimation, Université de Paris 6, Paris, 37 p.

[12] Yehuda, R. (2002) Post-Traumatic Stress Disorder. The New England Journal of Medicine, 10, 108-114.

[13] Anderson, W.G., Arnold, R.M., Angus, D.C. and Bryce, C.L. (2009) Passive Decision-Making Preference Is Associated with Anxiety and Depression in Relatives of Patients in the Intensive Care Unit. Journal of Critical Care, 24, 249-254.

https://doi.org/10.1016/j.jcrc.2007.12.010

[14] Pielmaier, L., Walder, B., Rebetez, M.M.L. and Maercker, A. (2011) Post-Traumatic Stress Symptoms in Relatives in the First Weeks after Severe Traumatic Brain Injury. Brain Injury, 25, 259-265. https://doi.org/10.3109/02699052.2010.542429 